\title{
THEORETICAL INVESTIGATION OF AGGREGATION OF TOP REMOVAL MACHINE FRONTALLY MOUNTED ON WHEELED TRACTOR
}

\author{
Volodymyr Bulgakov ${ }^{1}$, Valerii Adamchuk ${ }^{2}$, Semjons Ivanovs $^{3}$, Yevhen Ihnatiev ${ }^{4}$ \\ ${ }^{1}$ National University of Life and Environmental Sciences of Ukraine; \\ ${ }^{2}$ National Scientific Centre of Ukraine "Institute for Agricultural Engineering"; \\ ${ }^{3}$ Latvia University of Agriculture; ${ }^{4}$ Tavria State Agrotechnological University, Ukraine \\ semjons@apollo.lv
}

\begin{abstract}
At present the sugar beet top removal process is carried out without extraction of the beets from the soil, and it is implemented in two stages: at first, complete removal of the basic amount of the green mass without using a contour follower, followed by individual additional cleaning of the root crop heads from the top (leaf) residues. The use of top removal machines as independent harvesting moduli allows their aggregation with various types of row-crop tractors, which causes a necessity to determine conformity of this or other top removal machine with the traction and energy parameters in order to ensure high efficiency of using the proposed machine and tractor aggregates. The conducted investigations made it possible to develop a mathematical model for the justification and selection of optimal parameters of the machine and tractor aggregates composed of a tractor and a frontally mounted (frontal) top removal machine. In this connection, dependencies of the operating speed of the movement of a particular harvesting aggregate and its efficiency depending on the specific resistance of the top removal machine were determined in an analytical way. The numerical calculations performed on the PC provided a possibility to determine the optimal parameters of the mentioned aggregates by the efficiency and energy intensity criteria.
\end{abstract}

Key words: frontal top removal machine, aggregation, efficiency, parameters.

\section{Introduction}

Sugar beet is an important and highly profitable agricultural crop used to produce sugar and bioethanol as well $[1 ; 2]$. By the area under sugar beet the leading countries in Europe are: Ukraine, Russia, Germany, France, Turkey and Poland. The contemporary sugar beet top removal technologies envisage complete removal of the basic amount of the green mass without using a contour follower, followed by individual additional cleaning of the root crop heads from the top (leaf) residues [3; 4]. The first technological operation of removing the basic amount of the green mass presupposes the basic harvest of the yield (complete removal without using a contour follower, gathering the removed mass, and unloading), its transportation for subsequent use as animal forage, as a fertiliser or a raw material for biogas production. The use of the top removal machines as independent harvesting moduli allows their aggregation with various types of row-crop tractors. This causes a necessity to determine conformity of this or other top removal machine with the traction and energy parameters of the aggregating tractors in order to ensure high efficiency of using the proposed machine and tractor aggregates. However, high efficiency of operation of the agricultural machine and tractor harvesting aggregate will be achieved only on condition that there is correct correlation between its technical parameters and operation modes, and external production conditions, such as the physical and mechanical properties of the soil, field surface slopes, characteristics of the harvested material, specific resistance of the performed technological process, and other agrotechnical conditions [2]. Therefore, the issues of aggregating the top removal machines with various types of row-crop wheeled tractors are topical, and they need appropriate scientific justification.

The issues about theoretical research of aggregating agricultural machines, connected with constructing mathematical calculation models of operation of various self-propelled and trailed machine aggregates, have been sufficiently presented in scientific literature [5]. There are also articles [6] devoted to the construction of mathematical calculation models for trailed agricultural machines, including sugar beet and flax harvesters. The aggregation theory of trailed and rear-mounted agricultural machines is widely represented in fundamental works [8].

Fundamental issues concerning prognostication of the degree of raising the efficiency of the beet harvesting machines depending on specific investments are treated in the monograph [2]. However, the problems of the choice of optimal parameters of the frontally mounted beet harvesters by the efficiency criteria of the aggregating tractor are not discussed there. The methods how to obtain the 
performance characteristics of different machine and tractor aggregates composed of the aggregating tractors and hanged-on machines and tools are revealed in [8-10].

The efficiency of using aggregated beet harvesters should be estimated, first of all, in a complex with the aggregating tractor and by means of numerical criteria, which would reflect with a sufficient degree of accuracy their performance characteristics and technical perfection. Such criteria should include, first of all, the efficiency of such an aggregate, minimum operating costs, specific efficiency per $1 \mathrm{~kW}$ of the aggregating tractor power, and other efficiency indicators.

The aim of the work is to study and determine optimal aggregation parameters (maximal efficiency and minimal energy costs) of the top removal machine frontally mounted on a wheeled tractor of various types (different efficiency or draft category).

\section{Materials and methods}

The applied methods were: methods of the theory of mathematical simulation of agricultural machines and machine aggregates, the tractor theory, foundations of machine application in plant cultivation, as well as programme compilation and numerical calculations on the PC .

The use of the top removal machines as independent technological moduli in sugar beet harvesting allow their aggregation with various types of wheeled tractors equipped for this purpose with frontal lift linkages and frontal power take-off shafts. The aggregating tractor should be a rowcrop tractor, i.e. equipped with narrow tires mounted for a corresponding track width, i.e. for corresponding rows of sugar beet plantations. Besides, the top removal machines must be frontally mounted on the aggregating means of energy (tractor) since, after preliminary complete removal of the green mass and leaving the sugar beet roots in the soil, subsequent cleaning of the root crop heads from the remnants of the leaves, or cutting of the upper part of the roots, their heads, should be carried out. Such a subsequent cleaning or cutting of the root crop heads can be done by means of a tractor rear mounted cleaner.

We have developed a new design of a top removal machine, which performs complete cutting of the basic mass of the leaves without a contour follower, loading of the cut-off mass into a vehicle moving side by side and frontally mounted on the wheeled tractor (Fig. 1). This top removal machine may be made in various layout designs, i.e. for a different number of rows - in two to six-row variants.

For the analysis of efficient aggregating we will use commonly known dependencies to describe the theoretical efficiency of a top removal machine frontally mounted on the wheeled tractor. As the frontally mounted top removal machine is a driven aggregate (from the frontal power take-off shaft of the tractor), in order to determine its efficiency, it is necessary to have an equation of the traction balance and an equation of the power balance of the particular harvesting aggregate. In this case interrelation between the working width of the top removal machine and the speed of the machine and tractor aggregate can be described by such a well-known expression [10]:

$$
N_{e} \cdot \xi=\frac{R_{a} \cdot V_{r}}{3600 \cdot \eta_{t}(1-\delta)}+\frac{N_{p} \cdot B \cdot V_{r} \cdot H}{360 \cdot \eta_{v}},
$$

where $N_{e}-$ nominal efficient engine capacity, kW;

$\xi$ - engine loading factor;

$R_{a}$ - draft resistance of a top removal machine frontally mounted on the tractor, N;

$N_{p}$ - specific energy consumption of energy for the execution of the technological process of harvesting sugar beet tops, $\mathrm{kW} \cdot \mathrm{s} \cdot \mathrm{kg}^{-1}$;

$B$ - tworking width of the top removal machine, $\mathrm{m}$;

$V_{r}$ - speed of the aggregate, $\mathrm{km} \cdot \mathrm{h}^{-1}$;

$H$ - yield of sugar beet tops, cent ha ${ }^{-1}$;

$\eta_{t}$ - coefficient of efficiency of the transmission of a wheeled aggregating tractor;

$\eta_{v}$ - coefficient of efficiency of the frontal power take-off shaft of the tractor;

$\delta$ - skidding of the wheeled tractor.

Let us determine the components that enter into the expression (1). The draft resistance $R_{a}$ of the top removal machine frontally mounted on the tractor can be determined by means of such an expression: 


$$
R_{a}=R_{i}+R_{f}+R_{\text {top }}, \mathrm{N}
$$

where $R_{i}, R_{f}$ - resistance of the wheeled aggregating tractor to lifting and rolling, N;

$R_{\text {top }}$ - draft resistance of a top removal machine during the execution of the technological process of harvesting the sugar beet leaves, $\mathrm{N}$.

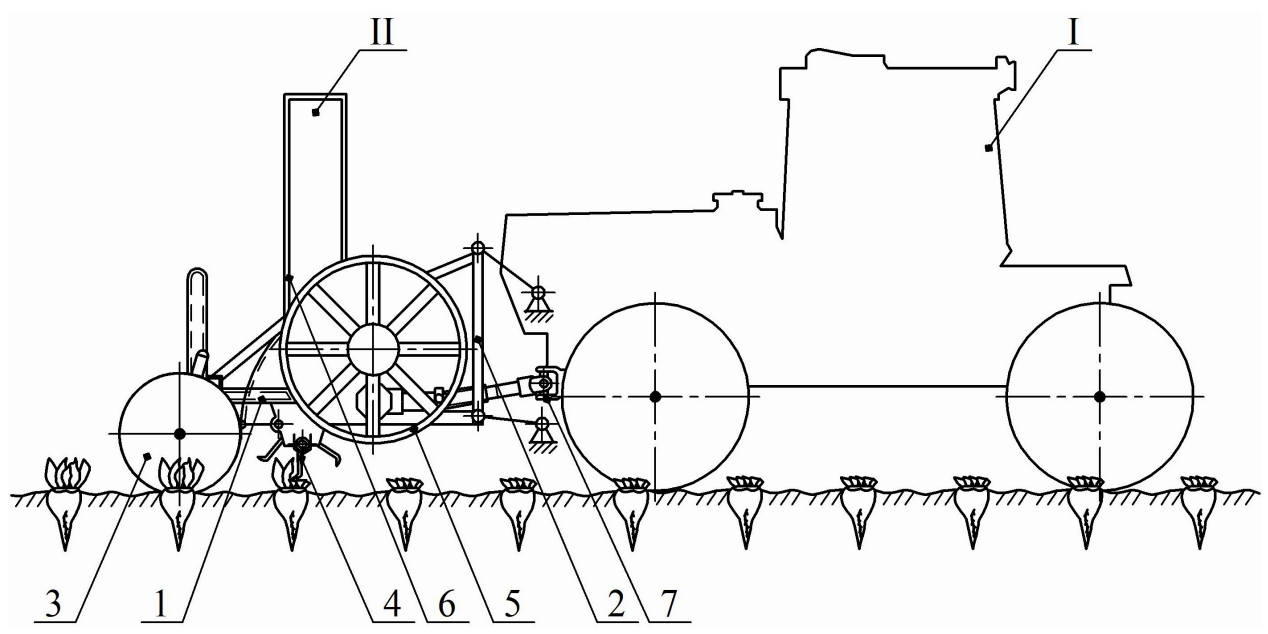

Fig. 1. Schematic layout of the aggregate for removing sugar beet leaves: I - wheeled row-crop tractor; II - frontally mounted top removal machine ( 1 - frame; 2 - frontal lift linkage; 3 - contour

follower wheel; 4 - rotary top cutting apparatus; 5 -transporting tool; 6 - loading device;

7 - transmission of the operating tools)

Since the product $N_{e} \cdot \xi$ in the equation of the draft balance (1) is numerically equal to the driving force of the wheeled aggregating tractor, which ensures overcoming of all the forces of resistance acting upon the particular top removal aggregate, the components of the expression (2) can be determined by means of such dependencies:

$$
\begin{gathered}
R_{i}=m g \cdot \sin \alpha, \\
R_{i}=m g \cdot \sin \alpha, \\
R_{t o p}=k \cdot B,
\end{gathered}
$$

where $\alpha$-angle of elevation, rad.;

$m$ - mass of the wheeled aggregating tractor, $\mathrm{kg}$;

$g-$ acceleration of gravity, $\mathrm{m} \cdot \mathrm{s}^{-2}$;

$f$ - rolling resistance coefficient of the wheeled aggregating tractor;

$k$-specific resistance of the frontally mounted top removal machine, $\mathrm{N} \cdot \mathrm{m}^{-1}$.

The rolling resistance coefficient $f$ of the wheeled tractor takes into consideration all the useful technological deformations carried out during the harvest of the sugar beet leaves, as well as the resistance to the movement of the frontally mounted top removal machine along the direction of its movement. At small angles of $\alpha$ the value $\sin \alpha \cdot 100$ is the elevation percentage $i$.

On the basis of expressions (2) and (3), (4) and (5) the equation (1) of the capacity of the aggregating tractor can be presented as:

$$
N_{e} \cdot \xi=V_{r} \frac{(k B+m g \cdot \psi) \eta_{v}+10 N_{p} B \cdot H \eta_{t}(1-\delta)}{3600 \cdot \eta_{t} \eta_{v}(1-\delta)},
$$

where $\psi$-resistance coefficient to the movement of the wheeled aggregating tractor.

In a general way the resistance coefficient $\psi$ to the movement of the wheeled tractor can be presented by the following dependency:

$$
\psi=\sin \alpha+f \cos \alpha
$$

where $\alpha$ - angle of elevation, rad;

$f$-rolling resistance coefficient of the tractor. 
By solving the equation (6) of the power balance of the wheeled aggregating tractor in relation to $V_{r}$ it is possible to determine the value of the speed of the particular top removal aggregate moving across the field:

$$
V_{r}=\frac{3600 \cdot \xi \cdot N_{e} \eta_{t} \eta_{v}(1-\delta)}{(k B+m g \psi) \eta_{v}+10 N_{p} B \cdot H \eta_{t}(1-\delta)}, \mathrm{km} \mathrm{h}^{-1} .
$$

In the analytical expression (8) for the determination of the speed $V_{r}$ of the movement of the wheeled aggregating tractor, together with a top removal machine frontally mounted on the tractor, which (the speed $V_{r}$ ) is needed to determine the efficiency of the particular machine and tractor harvesting aggregate, the coefficients $\xi, \eta_{t}$ and $\eta_{v}$ can be regarded as given. But it is necessary to determine skidding $\delta$ of the machine and tractor aggregate on the basis of various empirical formulas for constructing the skidding curve of the wheeled tractor. In this case we will use the known dependency for the determination of skidding $\delta$, which has the form [10]:

$$
\varphi=\varphi_{m}-a e^{-b \delta},
$$

where $\varphi$-coefficient of the use of the drawbar weight;

$\varphi_{m}$ - linkage coefficient;

$a, b$-constant coefficients, which depend on the type of the wheeled aggregating tractor and the agrobackground on which the removal of the sugar beet leaves takes place.

In the expression (9) the dependence of skidding $\delta$ on the coefficient of the use of the drawbar weight $\varphi$ is given implicitly, which impedes numerical calculations. In order to bring the expression (9) to a more convenient form, we will perform several algebraic transformations, on the basis of which we will obtain an expression for the determination of skidding $\delta$ in the following form:

$$
\delta=-\frac{1}{b} \ln \frac{\varphi_{m}-\varphi}{a} .
$$

Further, we will determine the coefficient $\varphi$ of the drawbar weight of the tractor, which enters into the expression (10), using such an analytical expression:

$$
\varphi=\frac{m g \cdot \psi+k B}{\lambda \cdot m g},
$$

where $\lambda$ - coefficient of the drawbar weight of the tractor.

Consequently, there is every reason to consider that all the values entered into in the expression (8) are given. Further, in order to determine the efficiency of the particular top removal aggregate, it is necessary to use a dependency [8] known from the course of the operation of the machine and tractor fleet:

$$
W=0.1 B \cdot V_{r}, \text { ha } \cdot \mathrm{h}^{-1},
$$

where $B$ - working width of the top removal machine frontally mounted on the wheeled tractor, $\mathrm{m}$; $V_{r}$ - speed of the forward movement of the aggregate, $\mathrm{km} \cdot \mathrm{h}^{-1}$.

By substituting into the expression (12) all the previously defined dependencies, we will finally obtain the value of the efficiency of the machine and tractor harvesting aggregate composed from a wheeled aggregating tractor and a frontally mounted top removal machine:

$$
W=0,1 B\left\{\frac{3600 \xi N_{e} \eta_{t} \eta_{v}\left[1+\frac{1}{b} \ln \frac{\left[\varphi_{m}-(m g \cdot \psi+k B)(m g \lambda)^{-1}\right]}{a}\right]}{(k B+m g \psi) \eta_{v}+10 N_{p} B H \eta_{t}\left[1+\frac{1}{b} \ln \frac{\left[\varphi_{m}-(m g \cdot \psi+k B)(m g \lambda)^{-1}\right]}{a}\right]}\right\} .
$$


The obtained expression (13) is a mathematical model of aggregation of the top removal machine frontally mounted on the wheeled tractor. Using this expression (13), we will determine the efficiency of the given machine and tractor aggregate depending on the initial parameters of this or that tractor and the top removal machines for a different number of rows and layout.

The technical characteristics of the integral all-purpose row-crop wheeled tractors (most widespread in Ukraine and neighbouring countries) with which it is possible to aggregate a frontally mounted top removal machine are given in Table 1 [10]. For a short (conditional) characteristic of a group of tractors with close parameters we will use a concept of the drawbar category accepted in some countries [8], which can more fully be characterised by a set of parameters: capacity, weight of the tractor, the torque moment, etc. The drawbar category is a technical characteristic of tractors defined by the greatest tractive force $(\mathrm{kN})$ developed by the tractor on a harvested field of cereals (stubble) at certain skidding (14-16\%).

Table 1

Technical characteristics of all-purpose row-crop tractors

\begin{tabular}{|c|c|c|c|c|c|}
\hline Drawbar category, function & $\mathbf{m g}, \mathbf{k g}$ & $\boldsymbol{N}_{\boldsymbol{e}}, \mathbf{k W}$ & $\boldsymbol{\varphi}_{\boldsymbol{m}}$ & $\boldsymbol{a}$ & $\boldsymbol{b}$ \\
\hline $9 \mathrm{kN}(\sim 40 \mathrm{HP})$, all-purpose row-crop, wheeled & 3000 & 36.8 & 0.6 & 0.75 & 8.81 \\
\hline $14 \mathrm{kN}(\sim 80 \mathrm{HP})$, all-purpose row-crop, wheeled & 3810 & 58.9 & 0.6 & 0.75 & 8.81 \\
\hline $30 \mathrm{kN}(\sim 150 \mathrm{HP})$, integral, row-crop, wheeled & 8200 & 117.7 & 0.65 & 0.753 & 9.52 \\
\hline
\end{tabular}

\section{Results and Discussion}

On the basis of the created programme of numerical calculations we carried out calculations of this mathematical model and constructed the corresponding graphs (Figs. 2-4).

While making numerical calculations, we took into account the agrotechnical requirements concerning the restrictions on forward speed of the top removal machine, which should be in the interval $1.5 \leq V_{r} \leq 4.0, \mathrm{~m} \cdot \mathrm{s}^{-1}$, as well as a restriction concerning adhesion of the actuators of the aggregating wheeled tractor with the soil when it moves across an unharvested sugar beet field. In this case the restriction has the form of:

$$
\varphi<\varphi_{m}
$$

For the given agrobackground, calculations were made for several types of aggregating wheeled tractors with which efficient operation of a frontally mounted top removal machine is possible. It should also be noted that we took into consideration a circumstance, while performing numerical calculations, that each type of a wheeled tractor of the corresponding drawbar category has it own mass $m$, engine capacity $N_{e}$, the coefficient $\lambda$. The values of the coefficients $\varphi_{m}, a$ and $b$ were selected specifically for the agrobackground on which the top removal machine is operated. Besides, for each variant of numerical calculations there were set: the yield of the sugar beet leaves $H$, specific energy consumption for the execution of the technological process $N_{p}$, maximum percentage of elevation $i$ of the slopes of the beet field, the rolling resistance coefficient $f$ of the tractor, the coefficient of efficiency of the frontal power take-off shaft of the tractor $\eta_{v}$. The coefficient of efficiency of the tractor transmission $\eta_{t}$ was selected for the wheeled tractors, equal to $\eta_{t}=0.92$. The specific resistance $k$ of the frontally mounted top removal machine was given for a different number or rows and varied with each type of the wheeled tractor in the interval from 1500 to $2700 \mathrm{~N} \cdot \mathrm{m}^{-1}$. Variations in the working width $B$ of the top removal machine frontally mounted on the tractor are within a range from $0.90 \mathrm{~m}$ to $2.7 \mathrm{~m}$, with a spacing $0.45 \mathrm{~m}$, i.e. from a two-row variant to a six-row variant.

For each variant of the numerical calculations, as the obtained results were defined: the specific resistance for each top removal machine of the respective working width and its corresponding speed $V_{r}$ of the movement of the given machine and tractor aggregate, its efficiency $W$, the draft resistance of the aggregate $R_{a}$, the coefficient of the use of the drawbar weight $\varphi$ and skidding $\delta$. Calculations according to the compiled mathematical model were carried out using set concrete (averaged) values of its parameters. Thus, for the numerical calculations it was assumed: the yield of the sugar beet leaves $-H=150$ cent $\cdot$ ha $^{-1}$; the specific consumption of energy for the execution of the technological process of harvesting the sugar beet leaves $-N_{p}=1.3 \mathrm{~kW} \cdot \mathrm{s} \cdot \mathrm{kg}^{-1}$; the coefficients $-\xi=0.90 ; \eta_{v}=0.95$; 
$f=0.07$; it was also assumed that there are not more than $5 \%$ of slopes on the sugar beet fields; the specific resistance of the frontally mounted top removal machine aggregated with a wheeled tractor (its average value) $k=1500-2700 \mathrm{~N} \cdot \mathrm{m}^{-1}$ (the step of variation in the specific resistance $\Delta k=200 \mathrm{~N} \cdot \mathrm{m}^{-1}$ ). For the given input parameters of the discussed system numerical calculations were made by the results of which graphs were constructed, presented in Figs. 2-4.

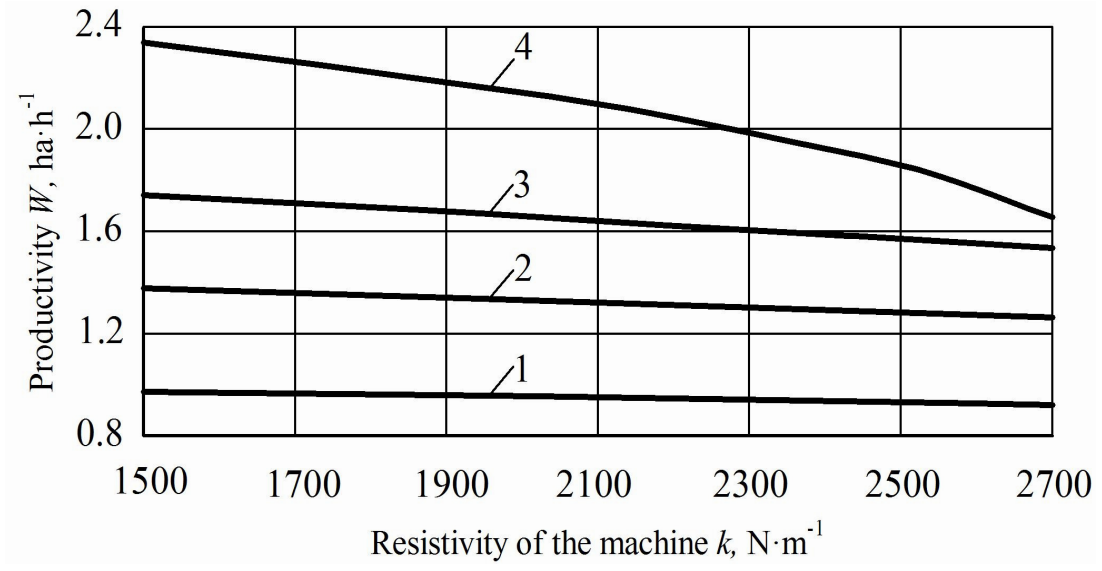

Fig. 2. Dependence of the efficiency $W$ of the top removal machine frontally mounted on the wheeled tractor, traction class 0.9 , on the specific resistance $k$ at various track widths: $1-B=0.9 \mathrm{~m}$ (a two-row variant); $2-B=1.35 \mathrm{~m}$ (a three-row variant); $3-B=1.8 \mathrm{~m}$ (a four-row variant); $4-B=2.7 \mathrm{~m}$ (a six-row variant)

As it is evident from the graphs above, aggregation of a top removal machine frontally mounted on the wheeled tractor is possible with any of the proposed aggregating tractors of various traction classes. Besides, in each graph the dependencies of the efficiencies $W$ of the top removal machines in a 2-row to 4-row executions upon the specific resistance $k$ are close to the linear ones. Aggregation of a frontally mounted top removal machine with the tractors of the traction class 0.9 (40 HP capacity) (Fig. 2) is unlikely to be considered purposeful because of the low efficiency $W$ of such aggregates.

As regards the use of the tractors of the traction class 1.4 (Fig. 3), in the case of significant increase in the specific resistance $k$, which may happen at a high yield of the leaves or at significant moisture of the soil (creating considerable resistance for the contour follower wheels of the top removal machine and causing adequate increase in the traction resistance of the entire aggregate) aggregation of the 6-row variant of the top removal machine does not ensure the necessary top removal efficiency.

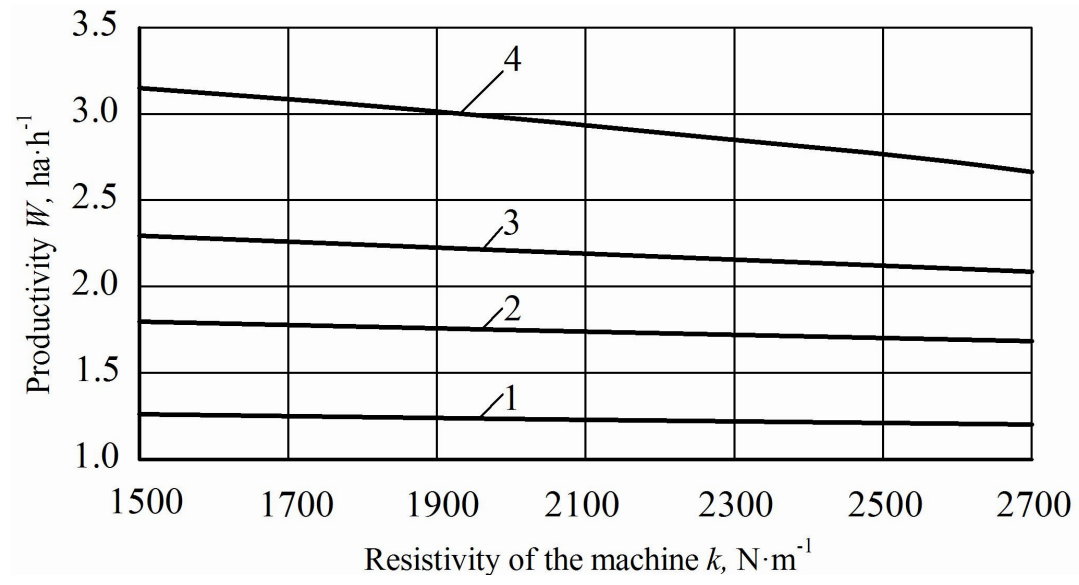

Fig. 3. Dependence of the efficiency $W$ of the top removal machine frontally mounted on the wheeled tractor, traction class 1.4 on the specific resistance $k$ at various track widths:

$$
1-B=0.9 \mathrm{~m} ; 2-B=1.35 \mathrm{~m} ; 3-B=1.8 \mathrm{~m} ; 4-B=2.7 \mathrm{~m}
$$

However, aggregation of the top removal machine in the 3-row and 4-row executions with the wheeled tractor of the traction class 1.4 ensures acceptable efficiency and is recommended for wide 
application in practice. And only in case when the integral, row-crop tractor of the traction class 3 (Fig. 4) is used as an aggregating tractor, aggregation of a frontally mounted top removal machine in a 6-row execution will be most purposeful from the operational and energetic points of view. For this aggregating tractor, variation in the specific resistance $k$ does not practically affect the efficiency $W$ of the frontally mounted top removal machine. High efficiency $W$ of the sugar beet top removal (more than $3.0 \mathrm{ha} \cdot \mathrm{s}^{-1}$ ), when the top removal machine is aggregated with the given type of tractors, is achieved for any yield of the leaves and soil conditions in the interrows of the sugar beet plantations.

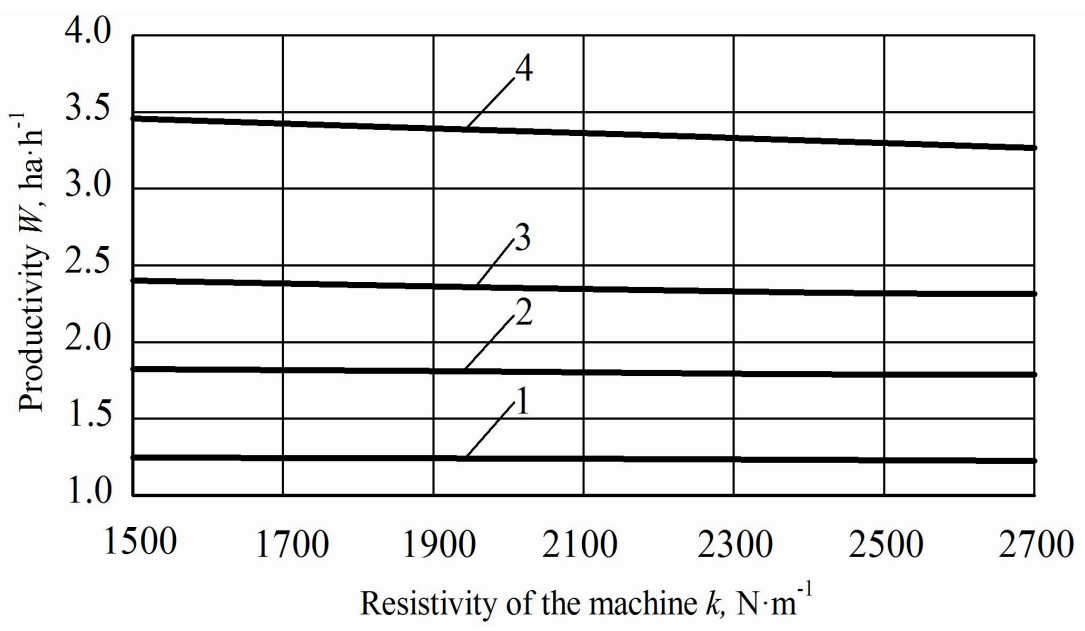

Fig. 4. Dependence of the efficiency $W$ of the top removal machine frontally mounted on the wheeled tractor, traction class 3 , on the specific resistance $k$ at various track widths:

$1-B=0.9 \mathrm{~m} ; 2-B=1.35 \mathrm{~m} ; 3-B=1.8 \mathrm{~m} ; 4-B=2.7 \mathrm{~m}$

It is quite obvious that the integral wheeled tractor of the traction class 3, equipped with a frontally mounted device and a frontal power take-off shaft, as well as a tractor equipped with narrow tires (in correspondence with the interrow width of the sugar beet plantations, equal to $0.45 \mathrm{~m}$ ), ensures efficient aggregation, together with a 6-row frontally mounted top removal machine, also a rear-mounted cleaner of the root crop heads from the leaf remnants, having a working width which corresponds to the 6-row variant. In this case, at high efficiency of aggregation, a complete machine and tractor aggregate will be formed for the removal of the sugar beet leaves.

\section{Conclusions}

1. On the basis of the conducted analytical investigations a mathematical model is obtained for the aggregation of top removal machines frontally mounted on a wheeled tractor to be used for theoretical determination (prognostication) of the operating speed and efficiency of various machine and tractor aggregates.

2. As a result of numerical simulation on the PC it was established that the wheeled tractor of the traction class 3 (150 HP capacity) will ensure efficiency more than $3.0 \mathrm{ha} \cdot \mathrm{h}^{-1}$ when a six-row frontally mounted top removal machine is aggregated at any values of the specific resistance, and, due to the efficiency reserve, there remains a possibility to use a rear-mounted cleaner of the sugar beet heads or a similar sugar beet harvesting machine.

3. The wheeled tractors of the classes 0.9 and 1.4 (with corresponding capacities 40 and $80 \mathrm{HP}$ ) will ensure stable efficiency (more than 1.7-2.2 ha $\cdot \mathrm{h}^{-1}$ ) only when two-row or three-row top removal machines are aggregated, having a low value of the specific resistance (low yields of the leaves, dry harvesting conditions, and so on).

\section{References}

1. Ivančan S., Sito S., Fabijanić G. Factors of the quality of performance of sugar beet combine harvesters. Bodenkultur, No 53(3), 2002. pp.161-166.

2. Булгаков В.М. Свеклоуборочные машины. Монография (Beet Harvesting Machines. А Monograph ). Kyiv, 2011, 351 p. (In Ukrainian). 
3. Lammers S., Olaf P., Olaf R. Defoliation of sugar beets - assessment of quality and gain in delivered beet mass, Landtechnik, 2010, No.3, pp. 464-467.

4. Bulgakov V., Ivanovs S., Golovach I., Ruzhylo Z. Theoretical investigations in cleaning sugar beet heads from remnants of leaves by cleaning blade. Engineering for rural development, Proceedings, Vol. 15, 2016, Jelgava, pp. 1090-1097

5. Bulgakov V., Ivanovs S., Adamchuk V., Boris A. Mathematical model for determination of losses of sugar bearing-mass when sugar beet tops are removed. Engineering for Rural Development, Proceedings, Vol. 14, 2015, pp. 41-45.

6. Булгаков В.М., Горбовой А.Ю. Теория движения льноуборочных комбайнов (The theory of the movement of flax combine harvesters). Lviv, 2007, 115 p. (In Ukrainian).

7. Кутьков Г.М. Тракторы и автомобили. Теория и технологические свойства (Tractors and automobiles. A theory and technological properties). Moskow, 2004, 504 p. (In Russian)

8. Надыкто В.Т. Основы агрегатирования модульных энергетических средств (Foundations of aggregation of modular energy facilities). Монография. Melitopol, 2003, 240 p. (In Ukrainian).

9. Kopiks, N., Viesturs, D., Valainis, O. Fleet of tractors on farms of Latvia, its structure and energy intensity. Engineering for rural development, Proceedings, Vol. 14, Jelgava, 2015, pp.84-87.

10. Пастухов В.И. и др. Справочник по машиноиспользованию в земледелии (Handbook on the machine use in agriculture). Charkov, 2001, 347 p. (In Russian) 